\title{
Evaluation of the CFP-substrate-YFP system for protease studies: advantages and limitations
}

\author{
Loyse M. Felber ${ }^{1}$, Sylvain M. Cloutier ${ }^{1,2}$, Christoph Kündig², Tadaaki Kishi ${ }^{3}$, Vincent Brossard $^{2}$, \\ Patrice Jichlinski ${ }^{1}$, Hans-Jürg Leisinger ${ }^{1}$, and David Deperthes ${ }^{1,2}$
}

BioTechniques 36:878-885 (May 2004)

\begin{abstract}
A protease can be defined as an enzyme capable of hydrolyzing peptide bonds. Thus, characterization of a protease involves identification of target peptide sequences, measurement of activities toward these sequences, and determination of kinetic parameters. Biological protease substrates based on fluorescent protein pairs, which allow for use of fluorescence resonance energy transfer (FRET), have been recently developed for in vivo protease activity detection and represent a very interesting alternative to chemical substrates for in vitro protease characterization. Here, we analyze a FRET system consisting of cyan and yellow fluorescent proteins (CFP and YFP, respectively), which are fused by a peptide linker serving as protease substrate. Conditions for CFP-YFP fusion protein production in Escherichia coli and purification of proteins were optimized. FRET between CFP and YFP was found to be optimum at a pH between 5.5 and 10.0, at low concentrations of salt and a temperature superior to $25^{\circ} \mathrm{C}$. For efficient FRET to occur, the peptide linker between CFP and YFP can measure up to 25 amino acids. The CFP-substrate-YFP system demonstrated a high degree of resistance to nonspecific proteolysis, making it suitable for enzyme kinetic analysis. As with chemical substrates, substrate specificity of CFP-substrate-YFP proteins was tested towards different proteases and kcat/Km values were calculated.
\end{abstract}

\section{INTRODUCTION}

Of all proteins expressed by living organisms, proteases are among the most critical in mediating pathways of cell life and death. Thus, there is an increasing need to rapidly determine the specificity of proteases that potentially play a role in human and animal diseases. Substrates for novel proteases can be discovered by testing standard protease substrates, by screening commercially available substrates for other proteases, or by preparing derivatives of known biological targets. Nevertheless, synthesis of chemical substrate remains complex and expensive. Moreover, addition of chemical compounds to peptide sequences can change the approach of an enzyme toward a substrate providing biased or wrong information on protease characteristics.

Mitra and colleagues (1) were the first to develop a protease substrate system based on the fluorescence resonance energy transfer (FRET) between two recombinant fluorescent proteins. This strategy consists of fusing covalently the two fluorescent proteins with a cleavable sequence. The emission spectrum of the donor protein overlaps the excitation spectrum of the acceptor enabling a transfer of energy. FRET only occurs if the two fluorophores are in very near vicinity of each other. Cleavage of the linker by a protease separates the two fluorophores and results in a loss of the energy transfer. Thus, hydrolysis of the substrate can be evaluated by the measurement of increasing fluorescence intensity of the donor and simultaneously decreasing fluorescence of the acceptor.

Cyan fluorescent protein (CFP) and yellow fluorescent protein (YFP) represent one of the most commonly used protein pairs exploited in FRET experiments. Their spectroscopic characteristics consist of well enough separated excitation and emission spectra but allow for efficient energy transfer between donor and acceptor. After excitation of CFP at $440 \mathrm{~nm}$, emission can be measured at $485 \mathrm{~nm}$ (CFP emission peak), and if FRET occurs, at $528 \mathrm{~nm}$ (YFP emission peak). The 528/485 nm fluorescence ratio can therefore be used as an index of FRET efficiency, even if there is a slight direct excitation of YFP at $440 \mathrm{~nm}$ and CFP emission at $528 \mathrm{~nm}$ (see Figure 1).

In the last few years, an increasing number of publications have reported the use of FRET technique to develop molecular probes for detection of in vivo action of proteases $(2,3)$. Curiously, FRET and fusion fluorescent proteins have never been exploited as alternative to synthetic substrates for monitoring enzyme activity in in vitro assays.

In the present work, we have determined optimal conditions to produce soluble CFP-YFP fusion protein. Different parameters influencing FRET 
have been studied, such as $\mathrm{pH}$, salt concentration, concentration of CFP-YFP, temperature, and length of the peptide linker between donor and acceptor, to define conditions of use. Different proteases have been tested to evaluate the potential limitation of the system.

\section{MATERIALS AND METHODS}

\section{Materials}

The following materials were obtained from commercial sources: shrimp alkaline phosphatase (Promega, Madison, WI, USA), T4 DNA ligase (Invitrogen, Carlsbad, CA, USA), T4 polynucleotide kinase (Qbiogene, Carlsbad, CA, USA), $\mathrm{Ni}^{2+}$-nitrilotriacetic acid agarose beads (Qiagen, Valencia, CA, USA). Synthesis of oligonucleotides was carried out by Invitrogen. The CFP and enhanced YFP (EYFP) cDNAs were a gift from Professor J. Tschopps' laboratory (Biochemistry Institute, Epalinges, Switzerland).

\section{Construction of CFP-(X)n-YFP Expression Vectors}

To construct plasmids expressing unconjugated CFP or YFP, cDNAs of fluorescent proteins were amplified by PCR with the following primers: 5'-CATCCAAAGGAGAAGAACT-3' (forward) and 5'-CTAAGCTTATTTGTATAGTT-3' (reverse). The PCR products were digested with the appropriate restriction enzymes (BamHI and HindIII) and subcloned in pQE9 vector (Qiagen).

For the CFP-YFP construct, the cDNA of fluorescent proteins were amplified by PCR with the following primers. For the CFP gene, a forward primer 5'-ATGGATCCATGAACTCCAAAGGAGAAG-3' and a reverse primer 5'-CCCAAGCTTGCGCGCCTTTGTATAGTTCATC-3' with BamHI and BssHII-HindIII restriction sites, respectively, were used, whereas for the EYFP gene, a forward primer 5'-TTGGCGCGCGTTAACGTCGACATCCAAAGGAGAAGAAC-3' and a reverse primer $5^{\prime}$-CCCAAGCTTAGTGATGGTGATGGTGATGAGATCTACTAGTTTTGTATAGTTCATC$3^{\prime}$ [encoding for a 6 histidine (His) tail] with BssHII-HpaI-SalI and HindIII restriction sites, respectively, were used.

A modified $\mathrm{pQE} 9$ vector with a deletion of the His-tag encoding sequence and the amplified CFP fragment were digested with BamHI and HindIII restriction enzymes and then ligated for

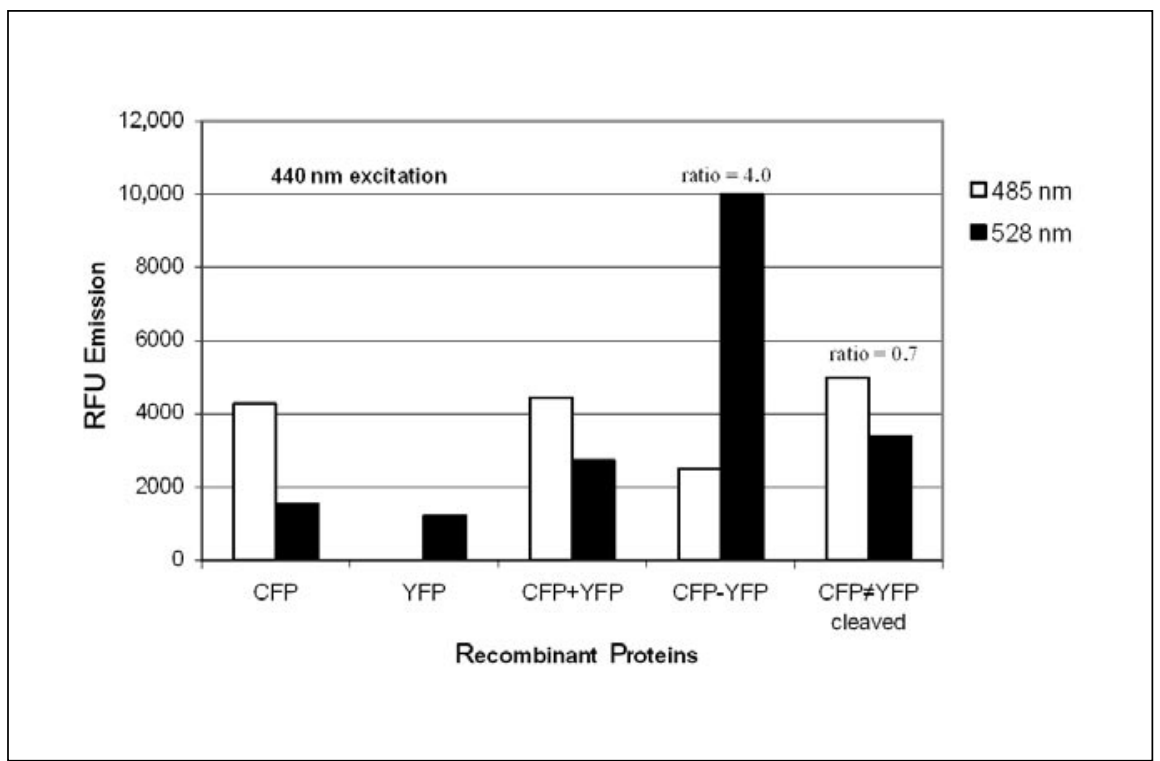

Figure 1. Fluorescence spectra of recombinant CFP and YFP proteins. Fluorescence at 485 and 528 $\mathrm{nm}$ was measured after excitation at $440 \mathrm{~nm}$. CFP, unconjugated CFP protein; YFP, unconjugated YFP protein; CFP+YFP, mixed unconjugated CFP and YFP proteins; CFP-YFP, CFP-YFP fusion protein (PCI-13); CFP $\neq$ YFP, fully hydrolyzed CFP-YFP fusion protein (PCI-13). PCI-13 (200 nM) was digested with $0.4 \mathrm{nM}$ chymotrypsin in reaction buffer. CFP, cyan fluorescent protein; YFP, yellow fluorescent protein; RFU, relative fluorescence units.

transformation in $E$. coli TG1 bacteria. The intermediate construction was digested with BssHII and HindIII restriction enzymes and ligated to the PCR-amplified YFP fragment digested with the same restriction enzymes. The resulting vector, pQC-STOP-Y, possesses a stop codon between the CFP and YFP genes and a histidine tail at its $\mathrm{C}$ terminal for affinity purification. The cloning of a cohesive DNA duplex encoding for a protease substrate sequence into the BssHII-SalI restriction sites of pQC-STOP-Y allows the production of a full-length fusion protein with histidine tail.

Several CFP-(X)n-YFP-6 $\times$ His recombinant proteins were constructed with varying lengths of linker between CFP and YFP proteins varying from 9 to 25 amino acids. These different constructs are described in the corresponding sections where they were used.

All expression constructs were confirmed by DNA sequencing (Syngene Biotech, Zürich, Switzerland). Secondary protein structures of peptide linkers were predicted using the program nnPredict (University of California UCSF, San Francisco, CA, USA).

\section{Optimization of CFP-Substrate-YFP Fusion Protein Production}

This experiment was carried out with the recombinant proteins PCI13 and G-13 containing the following amino acid sequences between CFP and YFP proteins: GALATFRSAAVST and GALAGGGGGAVST. From an overnight preculture, clones were grown in $10 \mathrm{~mL}$ of $2 \times$ tryptone yeast (TY) medium with ampicillin (100 $\mu \mathrm{g} / \mathrm{mL}$ ) at $37^{\circ} \mathrm{C}$ until absorbance (A) at $600 \mathrm{~nm}$ equals 0.6 and then induced varying the final concentrations of isopropyl $\beta$-D-thiogalactoside (IPTG) $(100 \mu \mathrm{M}, 1 \mathrm{mM})$, the expression temperatures $\left(16^{\circ}, 22^{\circ}, 30^{\circ}, 37^{\circ} \mathrm{C}\right)$, and the induction durations $(4 \mathrm{~h}, 16 \mathrm{~h})$. Induction conditions used in the CFP(X)n-YFP purification protocol were $100 \mu \mathrm{M}$ IPTG at $22^{\circ} \mathrm{C}$ for $16 \mathrm{~h}$.

The bacteria were harvested by centrifugation at $3500 \times g$ at $4^{\circ} \mathrm{C}$, and the pellet was suspended in $8 \mathrm{~mL}$ of cold phosphate-buffered saline (PBS), $\mathrm{pH}$ 7.4. A French press was used to recover the soluble fraction, which 
was characterized by sodium dodecyl sulfate (SDS) gel electrophoresis according to Laemmli and by Western blot analysis using a specific anti-His primary antibody (1/3000 dilution; Sigma, St. Louis, MO, USA), a mouse anti-Fab secondary antibody $(1 / 50,000$ dilution), and for detection the electrochemiluminescence (ECLTM) system (Amersham Biosciences, Piscataway, NJ, USA). A densitometry analysis using the digital camera system, Kodak Electrophoresis Documentation and Analysis System 290 (EDAS 290), and the software Kodak 1D (both from Eastman Kodak, Rochester, NY, USA) was performed to compare the levels of production under different conditions.

\section{Purification of CFP-(X)n-YFP Fusion Proteins}

Proteins were produced from a 10 $\mathrm{mL}$ bacteria culture at conditions determined above. The soluble fraction was mixed with $50 \mu \mathrm{L}$ of $\mathrm{Ni}^{2+}$-NTA agarose beads and incubated for $90 \mathrm{~min}$ at $4^{\circ} \mathrm{C}$ with gentle agitation to bind the recombinant proteins. The resin was washed three times with PBS containing 10 $\mathrm{mM} \beta$-mercaptoethanol and $20 \mathrm{mM}$ imidazole. Proteins were eluted with an elution buffer (PBS, $10 \mathrm{mM} \beta$-mercaptoethanol, $150 \mathrm{mM}$ imidazole) and dialyzed against a reaction buffer (50 $\mathrm{mM}$ Tris buffer, $\mathrm{pH} 8.3$, containing 100 $\mathrm{mM} \mathrm{NaCl}, 0.05 \%$ Triton ${ }^{\circledR} \mathrm{X}-100$ ) at $4^{\circ} \mathrm{C}$ overnight. The purity and quantity of the purified CFP-YFP recombinant proteins were evaluated by SDS polyacrylamide gel electrophoresis (SDSPAGE) followed by Coomassie ${ }^{\circledR}$ Blue staining.

\section{Fluorescence Measurement of Recombinant Fluorescent Proteins}

Fluorescence of CFP, YFP, and CFP$\mathrm{X}(\mathrm{n})$-YFP has been measured in 96-well black plates using a microplate fluorescence reader (Bio-Tek Instruments, Winooski, VT, USA) with excitation at $440 \mathrm{~nm}( \pm 15)$ and emissions at $485 \mathrm{~nm}$ $( \pm 10)$ and $528 \mathrm{~nm}( \pm 10)$. If not mentioned otherwise, measurements were taken in $50 \mathrm{mM}$ Tris, $\mathrm{pH} 7.5,150 \mathrm{mM}$ $\mathrm{NaCl}, 0.05 \%$ Triton X-100 with $200 \mathrm{nM}$ of substrate protein concentration.

\section{Effects of pH and Salt, Temperature, Length of Linkers, and Concentration on FRET}

These experiments were carried out with PCI-13 and G-13 recombinant proteins. FRET efficiency was calculated as the ratio between the two fluorescence intensities, 528 and $485 \mathrm{~nm}$. To test $\mathrm{pH}$ dependence of FRET, different buffers were prepared in order to obtain a gradient of $\mathrm{pH}$ from $\mathrm{pH} 4$ to $\mathrm{pH} 10$ : (i) $0.1 \mathrm{M}$ sodium acetate for $\mathrm{pH} 4.0$ to 5.5; (ii) $0.1 \mathrm{M}$ sodium phosphate for pH 5.5 to 8.5 ; and (iii) glycine- $\mathrm{NaOH}$ for $\mathrm{pH} 8.5$ to 10.0 . Triton was added to all buffers $(0.05 \%$ final concentration). The effect of salt on FRET was analyzed using different concentrations of $\mathrm{NaCl}: 20,50,100,200$, and $500 \mathrm{mM}$.

The efficiency of energy transfer and fluorescence of CFP-YFP fusion proteins was also evaluated at different temperatures $\left(4^{\circ}, 25^{\circ}, 30^{\circ}\right.$, and $37^{\circ} \mathrm{C}$ ) and various concentrations of proteins $(5 \mathrm{nM}$ to $50 \mu \mathrm{M})$ in reaction buffer (50 mM Tris-HCl, $\mathrm{pH}$ 8.0). This efficiency of FRET was also determined for different lengths of linkers between CFP and YFP $(9,13,19$, or 25 amino acids). The constructs used, G-9, G-13, G-19, and G-25, contain the following amino acid sequences between the CFP and YFP proteins: GAGGGGGST, GALAGGGGGAVST, GALGALAALAGGGGGAVST, and GALGALAALGALAALAGGGGGAVST, respectively.

\section{Kinetic Analysis of Proteases Using CFP-Substrate-YFP}

Substrate specificity of a CFP-substrate-YFP protein was tested towards different proteases. The recombinant protein PCI-13, at a concentration of $300 \mathrm{nM}$, was incubated with $5 \mathrm{nM}$ chymotrypsin, trypsin, or elastase or with $10 \mathrm{nM}$ plasma kallikrein. The reaction was performed for $30 \mathrm{~min}$ at $37^{\circ} \mathrm{C}$ in reaction buffer $[50 \mathrm{mM}$ Tris, pH 7.5, $150 \mathrm{mM} \mathrm{NaCl}, 0.05 \%$ Triton X-100, $0.01 \%$ bovine serum albumin (BSA)].

Substrate specificities of four different CFP-substrate-YFP proteins towards a protease were compared as follows: (i) $300 \mathrm{nM}$ of PCI-13 (PCIderived cleavage site); (ii) AT-13 ( $\alpha 1$ -
AT-derived cleavage site); (iii) CLS-13 (chymotrypsin-like substrate); and (iv) G-13 (protease-resistant peptide) corresponding to substrate sequences TFRSA, IPMSI, SQMVY, and GGGGG, respectively, were incubated with 0.4 $\mathrm{nM}$ chymotrypsin for $40 \mathrm{~min}$ at $37^{\circ} \mathrm{C}$ in reaction buffer $(50 \mathrm{mM}$ Tris, $\mathrm{pH} 7.5$, $150 \mathrm{mM} \mathrm{NaCl}, 0.05 \%$ Triton X-100, $0.01 \%$ BSA).

Substrate specificities were calculated by direct catalytic constant (kcat)/ Michaelis constant $(\mathrm{Km})$ determination. Using a substrate concentration far below the estimated $\mathrm{Km}$, it is possible to calculate an accurate value of $\mathrm{kcat} / \mathrm{Km}$ ratio under first-order conditions. Under these conditions, the substrate concentration is negligible in the lower part of the Michaelis equation, which therefore reduces to:

$$
-\mathrm{dS} / \mathrm{dt}=\mathrm{kcat} / \mathrm{Km} \times \mathrm{Et} \times \mathrm{S}
$$

where $\mathrm{dS} / \mathrm{dt}$ is the reaction velocity of the disappearance of the substrate, Et is the enzyme concentration, and $\mathrm{S}$ is the substrate concentration (4). The substrate hydrolysis obeys a first order process with the first-order rate constant (kobs). A continuous recording of the substrate hydrolysis will allow the graphical determination of kobs from the $\ln S$ versus time graph $(\mathrm{S}=\mathrm{So}-\mathrm{P})$. So is the starting substrate concentration (or total product), and $\mathrm{S}$ is the substrate concentration at a given time. The $\mathrm{kcat} / \mathrm{Km}$ ratio is simply inferred from kobs, providing the enzyme concentration is known: $\mathrm{kcat} / \mathrm{Km}=$ kobs/Et. After total hydrolysis of the substrate, evaluated on SDS-PAGE, the fluorescence units of the product will allow the accurate determination of So or Pt. The apparition of fluorescence, corresponding to product formation, has been measured with excitation at $440 \mathrm{~nm}( \pm 15)$ and emission at $485 \mathrm{~nm}( \pm 10)$.

\section{RESULTS AND DISCUSSION}

\section{Expression of CFP-YFP Fusion Protein}

To optimize the yield of CFP-YFP production, E. coli TG1 bacteria carrying CFP-(X)n-YFP constructs were induced at different temperatures $\left(16^{\circ}\right.$, 
$22^{\circ}, 30^{\circ}$, and $37^{\circ} \mathrm{C}$ ) and concentrations of IPTG $(0.1$ and $1 \mathrm{mM})$ for 4 or $16 \mathrm{~h}$. The protein yield of soluble CFP-YFP fusion protein was assessed by SDS-PAGE and Western blot analysis (Figure 2). Reducing the temperature of culture and concentration of IPTG radically improved soluble protein expression, which was maximal at $22^{\circ} \mathrm{C}$ and $0.1 \mathrm{mM}$ IPTG. Under these conditions, a long period of induction was required to allow the production of high levels of recombinant protein. Higher temperatures and/or IPTG concentrations lead to the production of recombinant proteins as inclusion body forms. The purification procedures developed for CFP-YFP proteins

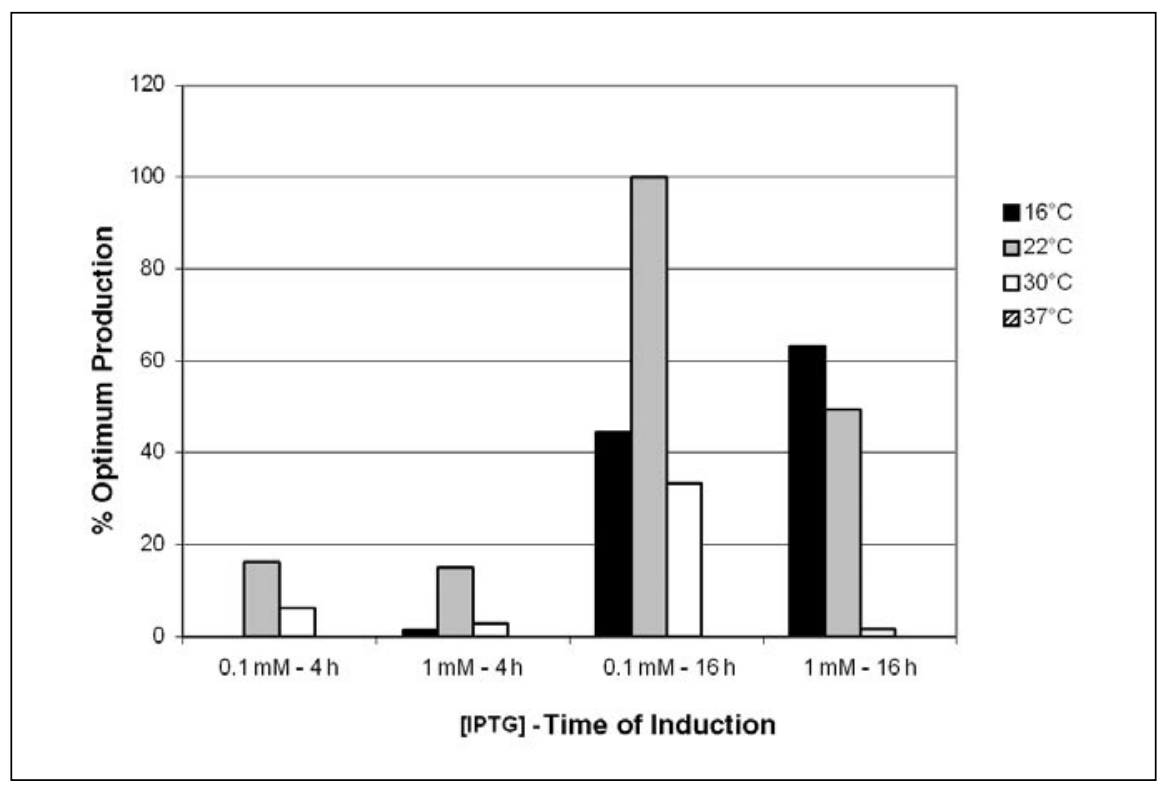

Figure 2. Production of CFP-substrate-YFP in different conditions of induction. Soluble extracts were separated by SDS-PAGE, and the level of CFP-YFP expression was quantified by densitometric scanning of Western blot analysis revealed with an anti-His antibody. Production was expressed in percentage of the optimal production of recombinant proteins. CFP, cyan fluorescent protein; YFP, yellow fluorescent protein; SDS-PAGE, sodium dodecyl sulfate polyacrylamide gel electrophoresis; IPTG, isopropyl $\beta$-D-thiogalactoside.

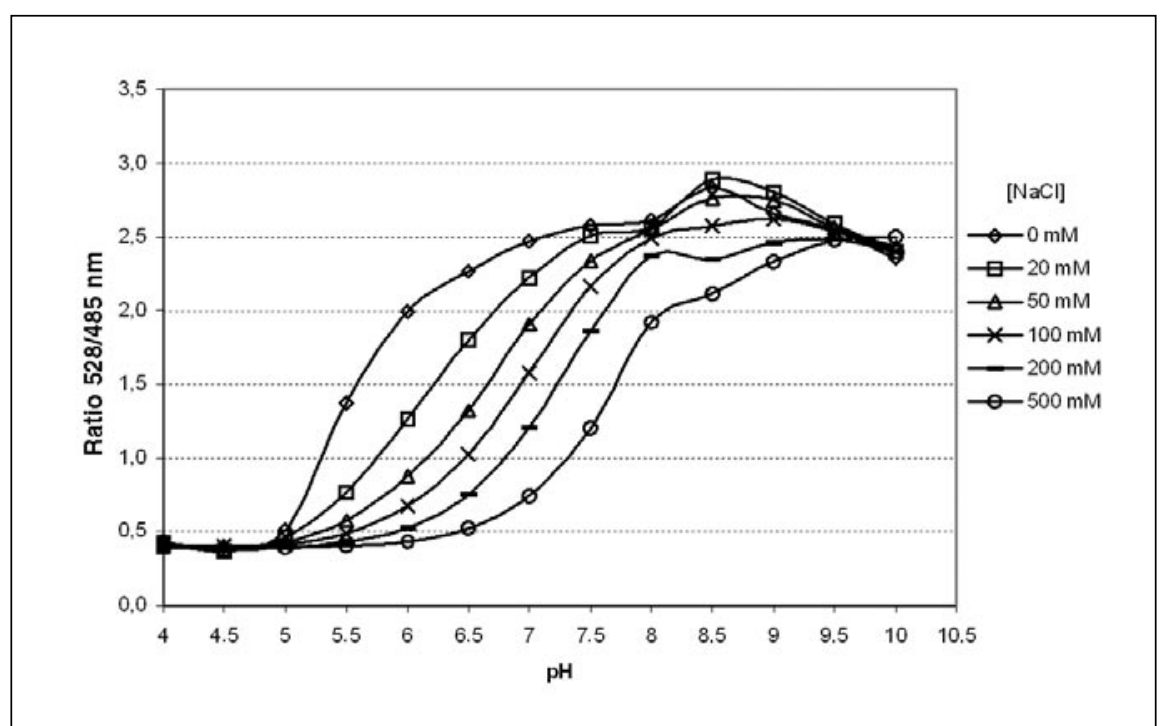

Figure 3. Influence of $\mathrm{pH}$ and salt concentration on $528 / 485 \mathrm{~nm}$ fluorescence ratio of CFP-YFP fusion proteins. CFP, cyan fluorescent protein; YFP, yellow fluorescent protein.

were very effective, and highly purified proteins were obtained (Figure 1 and not shown). Over 100 different CFP-YFP fusion proteins have been constructed and produced in our laboratory, and all of them gave a yield superior to $20 \mathrm{mg} / \mathrm{L}$ of bacterial culture, corresponding to a very good level of production.

The fluorescence properties of recombinant CFP, YFP, and CFP-substrate-YFP proteins after excitation at $440 \mathrm{~nm}$ are shown in Figure 1. CFP emits mainly at $485 \mathrm{~nm}$ and with lower intensity at $528 \mathrm{~nm}$. YFP on the other hand shows emission at $528 \mathrm{~nm}$ but not at $485 \mathrm{~nm}$. The intensity of emission is lowered compared to CFP due to nonoptimal excitation at 440 $\mathrm{nm}$. A mixture of unconjugated CFP and YFP protein gives roughly the addition of the two separate emission intensities. The CFP-substrate-YFP protein shows clear characteristics of FRET between CFP and YFP. CFP emission at $485 \mathrm{~nm}$ is decreased to energy transfer to YFP, and emission at $528 \mathrm{~nm}$ is largely increased due to efficient YFP excitation by CFP.

Separation of CFP and YFP by protease cleavage eliminates FRET between donor and acceptor, and therefore, the emission spectra of a cleaved CFP-YFP protein are almost identical to a mixture of unconjugated CFP and YFP, where emission at $485 \mathrm{~nm}$ is due to CFP, and emission at $528 \mathrm{~nm}$ is due to about $50 \%$ each CFP and YFP. Calculation of the ratio between emission at 528 and 485 $\mathrm{nm}$ is, therefore, a good indicator of FRET efficiency. Increasing values of $528 / 485 \mathrm{~nm}$ ratio indicate an increasing efficiency of FRET values and $\leq 0.7$ imply the absence of FRET.

\section{Effect of pH and Salt Concentrations on FRET}

Different proteases have $\mathrm{pH}$ optimums varying over a wide range. The $\mathrm{pH}$ can have an effect on the state of ionization of acidic or basic amino acids and thus changes not only the structure of the protease but also the ionization of the active site. Consequently, substrates used for protease characterization must be stable at various $\mathrm{pHs}$ to offer a broad scale of use. 
To evaluate the effect of $\mathrm{pH}$ on FRET, we placed CFP-YFP proteins at different $\mathrm{pHs}$ and measured the emission ratio between 528 and $485 \mathrm{~nm}$ reflecting the energy transfer between the two linked fluorescent proteins. If this ratio is $\leq 0.7$, no FRET has occurred (Figure 1). The highest ratio was obtained at $\mathrm{pH} 8.5$ with $20 \mathrm{mM}$ of $\mathrm{NaCl}$. As shown in Figure 3, pH has a big influence on FRET, which is not detectable at a pH below 5.0. This result is consistent with recent reports that showed the influence of $\mathrm{pH}$ on chromophore protonation states leading to a decrease of intensity of fluo- rescence $(5,6)$. Basic $\mathrm{pHs}$ have less impact on FRET, and 528/485 nm ratio values remain superior to 2.0 , even at $\mathrm{pH} 10.0$.

The presence or absence of salt is particularly important at $\mathrm{pH}$ 5.5-7.5. For example, at $\mathrm{pH} 7.0$, the ratio $528 / 485 \mathrm{~nm}$ was more than 2.5 in the absence of $\mathrm{NaCl}$, but only 0.7 when incubated with $500 \mathrm{mM} \mathrm{NaCl}$, indicating an absence of FRET under high salt conditions. The effect of chloride ions and similar halide anions on fluorescence of YFP is due to the binding near the chromophore $(7,8)$ at $\mathrm{pH}$ close to its $\mathrm{pKa}$, leading to a decrease of FRET. However, the sensitivity to halide ions could be counteracted by changing wild-type YFP for a new YFP named citrine, in which the mutation glutamine 69 to methionine confers insensitivity for halides (9).

In summary, the CFP-YFP system can be used in a range of $\mathrm{pH}$ from 5.5 to 10.0 in the absence or at low concentrations of chloride ions and in a $\mathrm{pH}$ range of 7.5 to10.0 with a concentration of chloride ions up to 500 $\mathrm{mM}$. These conditions correspond to the optimum $\mathrm{pH}$ ranges of the majority of proteases.

\section{Other Factors Influencing the FRET}

The temperature dependence of fluorescence of green fluorescent protein (GFP) variant proteins is well documented and some of them, like YFP V68L/Q69K, fluoresce only at a temperature below $20^{\circ} \mathrm{C}$ (9). We observed a similar behavior of intensity of fluorescence for CFP-YFP proteins with a fluorescence decrease of almost 2 -fold from $4^{\circ}$ to $37^{\circ} \mathrm{C}$ (Figure 4A). In contrast, FRET is hardly influenced by temperature, in which only a slight diminution of the $528 / 485 \mathrm{~nm}$ ratio was observed at $4^{\circ} \mathrm{C}$.

The essential requirements for energy transfer between the donor and the acceptor is a distance inferior to $100 \AA$ and a favorable orientation of the two chromophores relative to each other (10). The efficiency of energy transfer (E) is directly dependent on the distance ( $\mathrm{r}$ ) between the donor and acceptor chromophores, as described by the Förster equation (11):

$$
\mathrm{E}=\mathrm{R}_{0}^{6} /\left(\mathrm{R}_{0}^{6}+\mathrm{r}^{6}\right)
$$
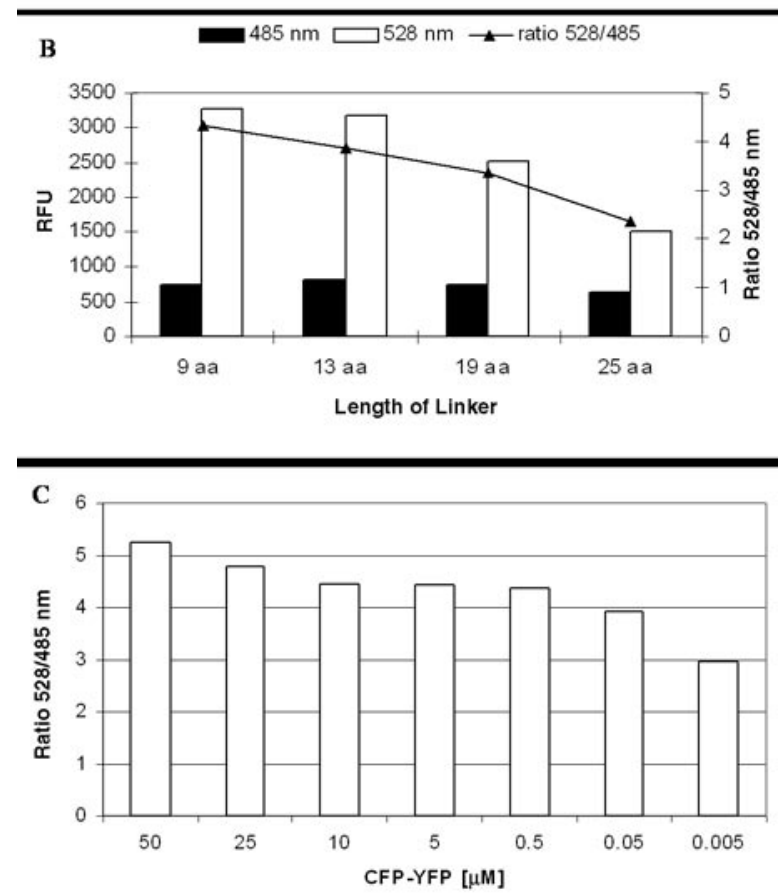

Figure 4. Effect of (A) temperature, (B) length of linker, and (C) concentration of CFP-YFP on efficiency of energy transfer from cyan to yellow fluorescent proteins. CFP, cyan fluorescent protein; YFP, yellow fluorescent protein; RFU, relative fluorescence units; aa, amino acid.

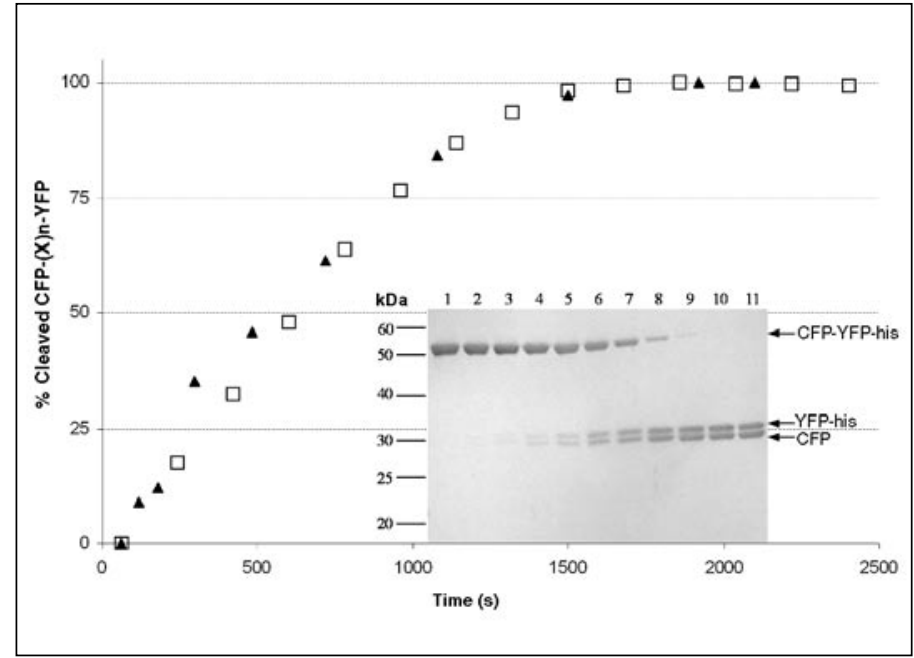

Figure 5. Correlation between CFP-YFP cleavage and increase of fluorescence at $485 \mathrm{~nm}$. The cleavage of CFP-YFP (AT-13) by elastase was quantified by densitometric analysis of Coomassie blue-stained SDS-PAGE $(\boldsymbol{\Delta})$. Fluorescence was measured at $485 \mathrm{~nm}$ after excitation at $440 \mathrm{~nm}(\square)$. AT-13 $(1 \mu \mathrm{M})$ substrate was incubated with $2.85 \mathrm{nM}$ of elastase at $37^{\circ} \mathrm{C}$. CFP, cyan fluorescent protein; YFP, yellow fluorescent protein; SDS-PAGE, sodium dodecyl sulfate polyacrylamide gel electrophoresis. 
where the Förster radius $\left(\mathrm{R}_{0}\right)$ is the distance at which the efficiency of energy transfer is $50 \%$. The $\mathrm{R}_{0}$ value for the CFP-YFP fluorophore was calculated to be about $50 \AA$ (12). Doubling the distance between acceptor and donor, from $r=R_{0}$ to $r=2 R_{0}$, will therefore decrease the efficiency $(E)$ of energy transfer from $50 \%$ to $1.5 \%$ and essentially no FRET can be observed at distances greater than $100 \AA$.

To evaluate the limitation in substrate peptide length, we introduced four different peptides ranging from 9 to $25 \mathrm{ami}-$ no acids (G-9, G-13, G-19, and G-25) between CFP and YFP. Indeed, we found a decreasing 528/485 $\mathrm{nm}$ ratio with increasing length of the peptide linker (Figure 4B). Nevertheless, the CFP-YFP system worked efficiently with all tested substrates containing peptide linkers of up to 25 amino acid (G-25). The 528/485 nm value of G-25 dropped to about $50 \%$. Protein secondary structure prediction programs predicted a mostly $\alpha$ helical conformation for this peptide linker, and the length was calculated to be about 50 $\AA$. The detected decrease of about $50 \%$ in 528/485 $\mathrm{nm}$ ratio for the fusion protein G-25 is, therefore, in good agreement with the predicted FRET decrease for a distance close to the Förster radius between CFP and YFP.

Evaluation of FRET levels in function of CFP-YFP concentration was done using increasing amounts of recombinant fluorescent protein (Figure 4C). FRET is quite stable from 0.05 to $25 \mu \mathrm{M}$ but slightly increases at higher concentration. As a rule, FRET should
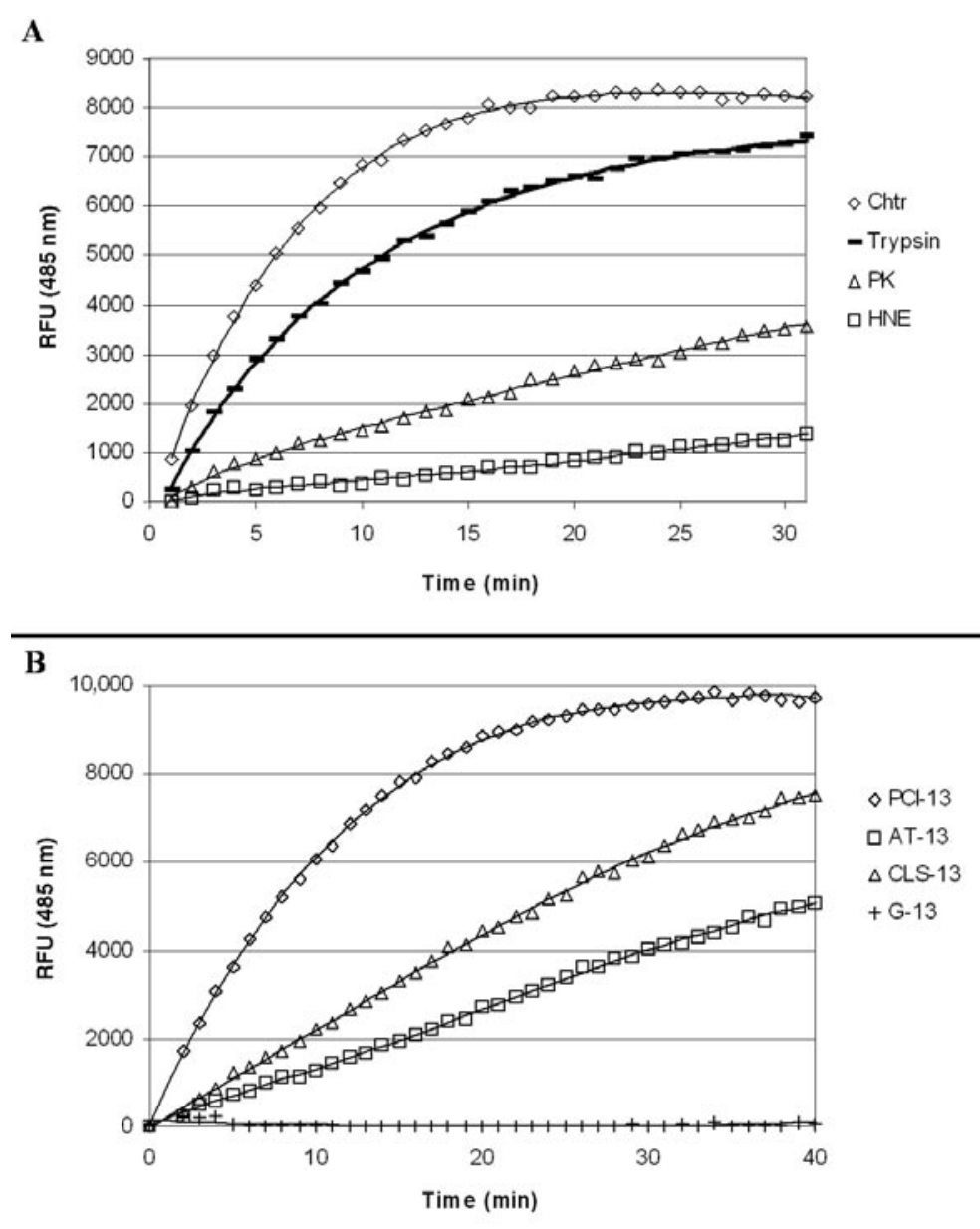

Figure 6. Kinetic analysis of protease cleavage of CFP-YFP-substrates. (A) Hydrolysis of PCI-13 by different proteases: chymotrypsin (Chtr), trypsin, elastase (HNE), and plasma kallikrein (PK). (B) Hydrolysis of different CFP-YFP substrates by chymotrypsin. Conditions of hydrolysis are described in Materials and Methods. Fluorescence at $485 \mathrm{~nm}$ was measured after excitation at $440 \mathrm{~nm}$. CFP, cyan fluorescent protein; YFP, yellow fluorescent protein; RFU, relative fluorescence units.

occur intramolecularly within the fusion CFP-YFP protein. However, promiscuity of fusion molecules at high concentrations can lead to intermolecular FRET, increasing indirectly the $528 / 485 \mathrm{~nm}$ ratio. The intermolecular FRET could be also due to the dimerization of CFP and/or YFP at high concentration, as described for GFP, which dimerizes at concentrations greater than $100 \mu \mathrm{M}$ (1). At $5 \mathrm{nM}$, close to the detection limit of fluorescence, the ratio is reduced to 3 . Nevertheless, the CFP-YFP system can be used in a large range of concentrations offering the possibility to determine $\mathrm{Km}$ of substrates or direct kcat $/ \mathrm{Km}$, which require low concentration of substrate.

\section{Versatility of CFP-YFP System for Protease Studies}

Over 400 potential proteases have been identified in the human genome. One of the major steps to understand their biological roles is the kinetic study with different substrates and inhibitors. Unfortunately, currently available substrates are limited and entail some problems. Fluorogenic substrates [e.g., 7-diethylamino-4methylcoumarin (AMC) substrates] are widely used for routine assays. The major drawback with these small peptides is the impossibility to study the $\mathrm{P}^{\prime}$ residues since position $\mathrm{P}^{\prime}$ is occupied by the fluorescence leaving group. The only possibility to study both $\mathrm{P}$ and $\mathrm{P}^{\prime}$ residues is the use of chemical, intramolecularly quenched substrates. As in CFP-YFP proteins, a peptide sequence separates a fluorescent donor group from an acceptor group that acts as a quencher of fluorescence. Nevertheless, the chemical properties of these two groups can change the affinity of the substrate towards an enzyme due to steric hindrance or electrostatic interactions. Moreover, the synthesis of these chemical substrates remains complex and expensive.

In this study, we demonstrate that the CFP-YFP system can be used in protease studies. The principle of this system is to insert a substrate peptide between CFP and YFP. Cleavage of the peptide bond within the substrate leads to the separation of the donor- 
acceptor associated with an increase of the fluorescence at $485 \mathrm{~nm}$. The excitation energy transferred from excited fluorescent donor (CFP), normally quenched by acceptor (YFP), is detected at $485 \mathrm{~nm}$ as emission fluorescence. The absence of emission fluorescence of YFP at $485 \mathrm{~nm}$ with excitation at $440 \mathrm{~nm}$ (Figure 1) demonstrates that the appearance of fluorescence measured at this wavelength is entirely due to CFP. Therefore, an increase of emission at $485 \mathrm{~nm}$ is due to an increase of free CFP. To validate this system, we compared the fluorescence increase to the amount of hydrolyzed CFP-substrate-YFP, evaluated on SDS-PAGE (Figure 5). In fact, we found an excellent correlation between fluorescence appearance at $485 \mathrm{~nm}$ and CFP-substrate-YFP cleavage. We tested this assay using one substrate with different enzymes and using different substrates with a single enzyme. Figure 6A demonstrates that the PCI13 protein, carrying the $\mathrm{PCI}$ reactive loop sequence (TFRSA) as substrate peptide linker, shows different sensitivities towards chymotrypsin, trypsin, elastase, and plasma kallikrein. Moreover, we demonstrated that is possible to compare different substrates, PCI13, AT-13, CLS-13, and G-13 for the same enzyme, chymotrypsin (Figure $6 \mathrm{~B})$. These data permit to calculate the $\mathrm{kcat} / \mathrm{Km}$ values for each substrate as described in the Material and Methods section. Using chymotrypsin, the calculated $\mathrm{kcat} / \mathrm{Km}$ values for PCI-13, AT-13, and CLS-13 are 3.6, 0.9, and $1.4 \times 10^{6} \mathrm{M}^{-1} \mathrm{~s}^{-1}$, respectively. The protease-resistant substrate G-13 with a GGGGG cleavage site was not cut by chymotrypsin, and even prolonged incubation hardly changed its fluorescence. This result is consistent with a study demonstrating that GFP resists efficiently to a wide range of proteases (13). However, some mutations can convert GFP to a proteolysis sensitive protein (14).

In summary, we demonstrated that the described CFP-YFP substrate system is working under conditions suitable for most of existing proteases. A big advantage is the ease of substrate production, allowing the construction of large numbers of substrates in a small period of time, at a very low cost in an entirely biological system without chemical manipulations. As with chemical substrates, this system enables the determination of $\mathrm{kcat} / \mathrm{Km}$ values describing substrate specificity. Moreover, it comprises no limitations due to restraints with residues acceptable in $\mathrm{P}^{\prime}$ positions of the substrate sequence or due to nonspecific interactions between large, hydrophobic fluorescent molecules and the protease.

\section{ACKNOWLEDGMENTS}

This work is supported by a grant from the Foundation OPO, Zürich, Switzerland.

\section{REFERENCES}

1.Mitra, R.D., C.M. Silva, and D.C. Youvan. 1996. Fluorescence resonance energy transfer between blue-emitting and red-shifted excitation derivatives of the green fluorescent protein. Gene 173:13-17.

2.Mahajan, N.P., D.C. Harrison-Shostak, J. Michaux, and B. Herman. 1999. Novel mutant green fluorescent protein protease substrates reveal the activation of specific caspases during apoptosis. Chem. Biol. 6:401-409.

3.Xu, X., A.L. Gerard, B.C. Huang, D.C. Anderson, D.G. Payan, and Y. Luo. 1998. Detection of programmed cell death using fluorescence energy transfer. Nucleic Acids Res. 26:2034-2035.

4.Fersht, A. 1985. Enzyme Structure and Mechanism, 2nd ed., p. 98-120. Freeman, New York.

5.Kneen, M., J. Farinas, Y. Li, and A.S. Verkman. 1998. Green fluorescent protein as a noninvasive intracellular $\mathrm{pH}$ indicator. Biophys. J. 74:1591-1599.

6.Elsliger, M.A., R.M. Wachter, G.T. Hanson, K. Kallio, and S.J. Remington. 1999. Structural and spectral response of green fluorescent protein variants to changes in $\mathrm{pH}$. Biochemistry 38:5296-5301.

7.Wachter, R.M. and S.J. Remington. 1999. Sensitivity of the yellow variant of green fluorescent protein to halides and nitrate. Curr. Biol. 9:628-629.

8.Jayaraman, S., P. Haggie, R.M. Wachter, S.J. Remington, and A.S. Verkman. 2000. Mechanism and cellular applications of a green fluorescent protein-based halide sensor. J. Biol. Chem. 275:6047-6050.

9.Griesbeck, O., G.S. Baird, R.E. Campbell, D.A. Zacharias, and R.Y. Tsien. 2001. Reducing the environmental sensitivity of yellow fluorescent protein. Mechanism and applications. J. Biol. Chem. 276:29188-29194.

10.Clegg, R.M. 1995. Fluorescence resonance energy transfer. Curr. Opin. Biotechnol. 6:103110.

11.Förster, T. 1948. Zwischenmolekulare Ener- giewanderung und Fluoreszenz. Ann. Physik (Leipzig) 2:55-75.

12.Elangovan, M., R.N. Day, and A. Periasamy. 2002. Nanosecond fluorescence resonance energy transfer-fluorescence lifetime imaging microscopy to localize the protein interactions in a single living cell. J. Microsc. 205:3-14.

13.Bokman, S.H. and W.W. Ward. 1981. Renaturation of Aequorea green-fluorescent protein. Biochem. Biophys. Res. Commun. 101:1372-1380.

14.Chiang, C.F., D.T. Okou, T.B. Griffin, C.R. Verret, and M.N. Williams. 2001. Green fluorescent protein rendered susceptible to proteolysis: positions for protease-sensitive insertions. Arch. Biochem. Biophys. 394:229-235.

Received 8 December 2003; accepted 1 March 2004.

Address correspondence to:

David Deperthes

Urology Research Unit, Biopôle

Ch. Croisettes 22, CH-1066 Epalinges

Switzerland

e-mail:david.deperthes@urology-research.ch 